\title{
OPERATOR ALLOCATION SELECTION IN LABOR-INTENSIVE MANUFACTURING SYSTEM USING AHP/DEA AND DEA
}

\author{
Ruzanita Mat Rani* \\ Centre for Statistical and Decision Sciences Studies, Faculty of Computer and Mathematical Sciences \\ Universiti Teknologi MARA, 40450 Shah Alam, Selangor, Malaysia \\ E-mail: $\underline{\text { ruzanita@tmsk.uitm.edu.my }}$ \\ Wan Rosmanira Ismail \\ School of Mathematical Sciences, Faculty of Science and Technology, Universiti Kebangsaan Malaysia, \\ 43600 UKM Bangi, Selangor, Malaysia \\ E-mail: wrismail@ukm.my
}

\begin{abstract}
Operator allocation is one of the most important decisions that can influence productivity in the laborintensive manufacturing system. In this paper 10 operator allocation alternatives are identified with the assistance of computer simulation. To determine the best operator allocation, AHP/DEA and DEA Cross Efficiency are used. The results of both techniques are compared. Based on the results, alternative given by AHP/DEA model is the best since it has the smallest number of operators and only used one assembly line.
\end{abstract}

Keywords: operator allocation, AHP/DEA, DEA

\section{Introduction}

One of the most important decisions that can affect productivity in labor-intensive manufacturing system is the allocation of operators to various operations. The operator allocation decision is related with "who works where?"(Majozi \& Zhu, 2005). The determination of the optimum staffing level in the production line is the objective of operator allocation decision. Krishnan et al. (2012) mentioned that for a laborintensive manufacturing system, operator allocation affects company's throughput and cost. Weak decision on operator allocation will reduce company's throughput and increase waste.

Hence the importance of the allocation of operators in manufacturing systems is paramount. There are some literatures on various methods in determining the best operator allocation. For example, Azadeh et al. (2011a), Azadeh et al. (2011b), Zohrehbandian et al. (2011), Azadeh et al. (2010), Yang et al. (2007) and Ertay and Ruan (2005) used different approaches to find the best operator allocation. Most of previous studies used two phases methodology. The first phase is to determine the inputs and outputs for operator allocation alternatives and in the second phase find the best operator allocation. As depicted in Table 1 the phases involved in previous studies. All operators are treated to have the same level of performances and the operator allocation is normally based on operational constraints.

In reality, operator allocation decisions becomes much more important issue faced by the management of the company. This problem caused by the differences in the operator's level of skills and experience and different job requirement at each workstation in production line. Currently, the operator allocation decision is made by management based on experience and trial and error method.

\footnotetext{
* Corresponding author
} 
Table 1. Previous Researches on Operator Allocation.

\begin{tabular}{|c|c|c|c|c|c|c|c|c|c|c|c|}
\hline \multirow{3}{*}{ Authors } & \multirow{3}{*}{ Year } & \multicolumn{10}{|c|}{ Solution Approach } \\
\hline & & \multirow{2}{*}{$\begin{array}{c}\text { Phase } 1 \\
\text { Computer } \\
\text { Simulation }\end{array}$} & \multicolumn{9}{|c|}{ Phase 2} \\
\hline & & & 要 & 胥司 & 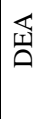 & 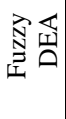 & 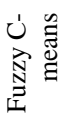 & $\mid \begin{array}{l}n \\
\tilde{n} \\
\tilde{0} \\
\ddots\end{array}$ & 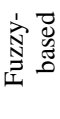 & 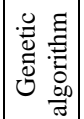 & 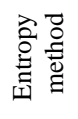 \\
\hline Azadeh, Kor, and Hatefi & 2011 & $\checkmark$ & & & & & & $\checkmark$ & & $\checkmark$ & $\checkmark$ \\
\hline $\begin{array}{l}\text { Azadeh, Nazari-shirkouhi, Hatami } \\
\text { shirkouhi and Ansarinejad }\end{array}$ & 2011 & $\checkmark$ & & $\checkmark$ & & & & $\checkmark$ & & & \\
\hline $\begin{array}{l}\text { Zohrehbandian, Abbasian-Naghneh, } \\
\text { Fardi, and Moradi }\end{array}$ & 2011 & $\checkmark$ & & & $\checkmark$ & & & & & & \\
\hline Azadeh, Anvari, Ziaei, and Sadeghi & 2010 & $\checkmark$ & & & & $\checkmark$ & $\checkmark$ & & & & \\
\hline Yang, Chen, and Hung & 2007 & $\checkmark$ & $\checkmark$ & & & & & $\checkmark$ & $\checkmark$ & & \\
\hline Ertay and Ruan & 2005 & $\checkmark$ & & & $\checkmark$ & & & & & & \\
\hline
\end{tabular}

Consequently the company may not fully use their skilled and experienced operators. Therefore, this paper aims to improve the performance of production line of a disk drive components manufacturing plant by determining the best operator allocation by using 2 different methods.

Table 2. Proposed Alternatives for Operator Table 3. Inputs and Outputs Based on Simulation Allocation

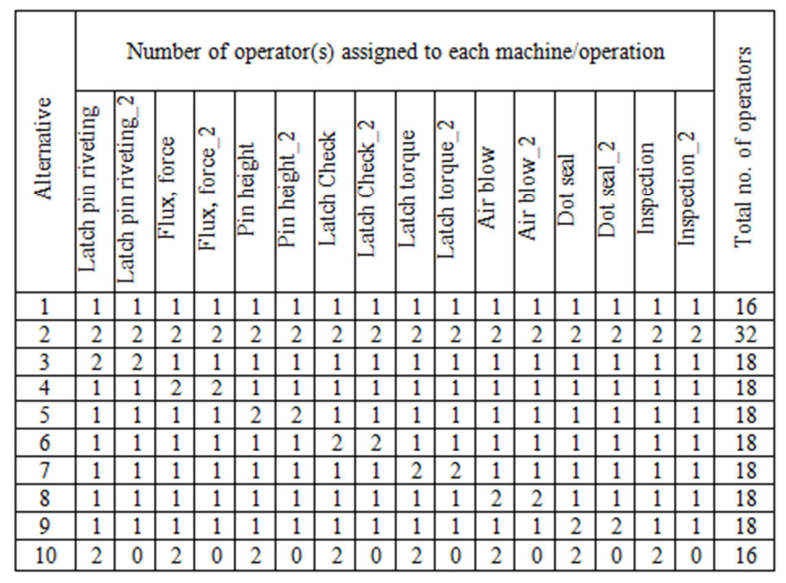
Results.

\begin{tabular}{|c|c|c|c|c|}
\hline \multirow[b]{2}{*}{$\mathrm{DMU}$} & \multicolumn{2}{|c|}{ Input } & \multicolumn{2}{|c|}{ Output } \\
\hline & $\begin{array}{l}\text { Average } \\
\text { cycle } \\
\text { time } \\
\text { (seconds) }\end{array}$ & $\begin{array}{l}\text { Average } \\
\text { waiting } \\
\text { time } \\
\text { (seconds) }\end{array}$ & $\begin{array}{c}\text { Total } \\
\text { parts } \\
\text { produced } \\
\text { (units) }\end{array}$ & $\begin{array}{l}\text { Average } \\
\text { operator } \\
\text { utilization }\end{array}$ \\
\hline 1 & 90.325 & 17.668 & 6461 & 0.636 \\
\hline 2 & 72.694 & 0.034 & 6466 & 0.410 \\
\hline 3 & 94.051 & 21.388 & 6466 & 0.761 \\
\hline 4 & 90.328 & 17.679 & 6463 & 0.760 \\
\hline 5 & 95.769 & 23.105 & 6462 & 0.750 \\
\hline 6 & 87.600 & 14.930 & 6465 & 0.755 \\
\hline 7 & 89.576 & 16.903 & 6463 & 0.760 \\
\hline 8 & 90.325 & 17.668 & 6461 & 0.780 \\
\hline 9 & 91.616 & 18.949 & 6461 & 0.760 \\
\hline 10 & 72.795 & 0.139 & 6466 & 0.820 \\
\hline
\end{tabular}

There are two assembly lines in Clean Room 2 at this manufacturing plant whereby each line is running the same operation. All operations in Clean Room 2 are semi-auto machine where one operator is assigned to one machine. There is one machine for each operation. The operation involved in Clean Room 2 are latch pin riveting; flux, force and latch movement check; pin height and parallelism check; latch check; latch torque testing; air blow; dot seal pasting; inspection and final cleaning. As shown in Table 2 10 operator allocation alternatives are proposed and with the assistance of computer simulation, inputs and outputs for 10 operator allocation alternatives are generated. The inputs and outputs based on simulation results are given in Table 3.

\section{Evaluation Method}

Data Envelopment Analysis (DEA) is a linear programming based technique to measure the relative efficiency of homogeneous decision making units (DMUs). It was introduced by Charnes, Cooper, and Rhodes (1978) and is used to measure DMUs relative efficiency based on selected inputs and outputs. In this paper CCR model is used to determine the best operator allocation. The CCR model is as follows. 
$\max h_{0}=\sum_{r=1}^{s} u_{r} y_{r j_{0}}$

subject to

$\sum_{i=1}^{m} v_{i} x_{i j_{0}}=1, \quad \sum_{r=1}^{s} u_{r} y_{r_{j}}-\sum_{i=1}^{m} v_{i} x_{i_{j}} \leq 0, j=1, \ldots, n$,

$u_{r}, v_{i} \geq 0$, for all $r, i$ and $j$,

where $h_{0}$ is the relative efficiency of $\mathrm{DMU}_{0}$, i.e. the DMU under evaluation, $j$ is the DMU index, $r$ is the output index, $i$ is the input index, $y_{r j}$ is the value of the $r^{\text {th }}$ output for the $j^{\text {th }}$ DMU, $x_{i j}$ is the value of the $i^{\text {th }}$ input for the $j^{\text {th }}$ DMU, $u_{r}$ is the weight given to the $r^{\text {th }}$ output and $v_{i}$ is the weight given to the $i^{\text {th }}$ input.

$\mathrm{DMU}_{0}$ is efficient (selected) if $h_{0}=1$, on the other hand if $h_{0}<1$, the alternative is inefficient (not selected). However when using DEA, it may occur that there are more than one DMUs which are efficient. To choose the best alternative among the efficient DMUs, we used the reference set. That is we determine how many times each efficient DMU is being referred to by the inefficient DMUs. The higher the number of reference set, the higher is the rank. Therefore, in this paper two different approaches will be used to overcome this problem which are AHP/DEA and DEA Cross Efficiency. These two methods will rank the alternatives.

\subsection{AHP/DEA}

Analytical Hierarchy Process (AHP) is a method for ranking several decision alternatives and selecting the best one when the decision maker has multiple objectives or criteria on which to base the decision. It was introduced by Saaty (1980). There are two main stages in AHP/DEA methodology to rank the alternatives. The AHP/DEA methodology was stated in Sinuany-Stern et al. (2000). In the first stage is the pairwise comparison matrix through DEA model. Suppose there are $n$ DMUs, each unit has $s$ output and $m$ input, $r$ is the output index, $i$ is the input index, $y_{r j}$ is the value of the $r^{\text {th }}$ output for the $j^{\text {th }}$ DMU, $x_{i j}$ is the value of the $i^{\text {th }}$ input for the $j^{\text {th }}$ DMU. For any pair of DMUs, for example DMU $A$ and DMU $B$, we perform the following DEA model. $E_{A A}$ is the value of pairwise comparison. It represents the comparison of efficiency DMU $A$ with DMU $B$.

$E_{A A}=\max Z_{A A}=\sum_{r=1}^{s} u_{r} y_{r A}$

subject to

$\sum_{i=1}^{m} v_{i} x_{i A}=1, \quad \sum_{r=1}^{s} u_{r} y_{r A} \leq 1, \quad \sum_{r=1}^{s} u_{r} y_{r B}-\sum_{i=1}^{m} v_{i} x_{i B} \leq 0$,

$u_{r}, v_{i} \geq 0$

$E_{B A}$ is the cross evaluation of DMU $B$ by using optimal weights of DMU $A\left(E_{A A}\right)$. After $E_{A A}$ and $E_{B A}$ values are obtained, then $E_{B B}$ and $E_{A B}$ must be solved.

$E_{B A}=\max Z_{B A}=\sum_{r=1}^{s} u_{r} y_{r B}$

subject to

$\sum_{i=1}^{m} v_{i} x_{i B}=1, \quad \sum_{r=1}^{s} u_{r} y_{r B} \leq 1, \quad \sum_{r=1}^{s} u_{r} y_{r A}-E_{A A} \sum_{i=1}^{m} v_{i} x_{i A}=0$

$u_{r}, v_{i} \geq 0$ 
Based on the results using DEA models, for each pair of DMUs, considering DMU $A$ as DMU $j$ and DMU $B$ as DMU $k$, Sinuany-Stern et al. (2000) construct $N x N$ pairwise comparison matrix $\boldsymbol{A}=\left[a_{j k}\right]$. The $a_{j k}$ element of pairwise comparison matrix is calculated as follows.

$$
a_{j k}=\frac{E_{j j}+E_{j k}}{E_{k k}+E_{k j}}
$$

In the second stage is to rank the alternatives through AHP model. The AHP rank is a single hierarchical level based on matrix A. Calculate the maximum Eigen value $\left(\lambda_{\max }\right)$ and its Eigen vector $(\vec{w})$. DMU with the maximum value of $\vec{w}$ will be in the first rank.

\subsection{DEA Cross Efficiency}

Cross efficiency is based on self assessment and peer assessment and can be calculated in two phases. The first phase is derived from DEA model (1), where the score for $\mathrm{DMU}_{0}$ is $h_{0}$ or it is based on self assessment. In the second phase the peer assessment score of $\mathrm{DMU}_{t}$ is calculated using the optimal weights that $\mathrm{DMU}_{0}$ has chosen in model (1). The peer assessment formula is given by Doyle and Green (1994):

$$
E_{p t}=\frac{\sum_{r=1}^{s} u_{r p} y_{r t}}{\sum_{i=1}^{m} v_{i p} x_{i t}} \quad p, t=1,2, \ldots, n
$$

where, $E_{p t}$ is the score for $\mathrm{DMU}_{t}$ using the optimal weights selected by $\mathrm{DMU}_{p}, y_{r t}$ is the value of the $r^{\text {th }}$ output for $\mathrm{DMU}_{t}, x_{i t}$ is the value of the $i^{\text {th }}$ input for $\mathrm{DMU}_{t}, u_{r p}$ is the weight given to the $r^{\text {th }}$ output for $\mathrm{DMU}_{p}$ and $v_{i p}$ is the weight given to the $i^{\text {th }}$ input for $\mathrm{DMU}_{p}$. The cross efficiency score for $\mathrm{DMU}_{t}$ or the average of all $E_{p t}$ can be calculated as follow:

$$
\overline{E_{t}}=\frac{1}{n} \sum_{p=1}^{n} E_{p t}
$$

The self assessment score from model (1) and peer assessment score from (5) can be organized in a matrix. A DMU with the highest average of all $E_{p t}$ is categorized as the optimal operator allocation.

\section{Results}

The DEA results from model (1) are solved using LINGO software and presented in Table 4. Based on efficiency score, DMU 2 and DMU 10 are efficient. Based on the results of the reference set shown in Table 4, we can conclude that both DMUs have the same rank since they have the same number of reference sets of 8. Therefore to choose the best alternative, AHP/DEA and DEA Cross Efficiency will be used.

Table 4. Efficiency Score and Reference Set for 10 Operator Allocation Alternatives

\begin{tabular}{|c|c|c|c|c|c|c|c|c|c|c|}
\hline $\begin{array}{c}\text { Alternative, } \\
\text { DMU }_{0}\end{array}$ & 1 & 2 & 3 & 4 & 5 & 6 & 7 & 8 & 9 & 10 \\
\hline $\begin{array}{c}\text { Efficiency } \\
\text { Score, } \\
h_{0}\end{array}$ & 0.80480 & 1.0000 & 0.77384 & 0.80536 & 0.75946 & 0.83068 & 0.81212 & 0.80519 & 0.79379 & 1.00000 \\
\hline $\begin{array}{c}\text { Reference } \\
\text { Set, } \text { DMU }_{0}\end{array}$ & 2,10 & 2 & 2,10 & 2,10 & 2,10 & 2,10 & 2,10 & 2,10 & 2,10 & 10 \\
\hline
\end{tabular}

\subsection{AHP/DEA}

The pairwise comparison matrix is constructed using (2), (3) and (4) in order to rank the alternatives. The pairwise comparison matrix is shown in Table 5. To determine the best alternative, maximum of Eigen vector will be identified.

\subsection{DEA Cross Efficiency}

In order to determine the best alternatives, cross efficiency scores are calculated. The score from cross efficiency matrix can be calculated using model (1) and (5). The cross efficiency matrix is shown in Table 6. To rank the alternatives, the average of all $E_{p t}$ is calculated using (6). 
Table 5. Pairwise Comparison Matrix

\begin{tabular}{|c|c|c|c|c|c|c|c|c|c|c|}
\hline $\begin{array}{c}\text { Alternative, } \\
\mathrm{DMU}_{0}\end{array}$ & 1 & 2 & 3 & 4 & 5 & 6 & 7 & 8 & 9 & 10 \\
\hline 1 & 1.00000 & 1.00000 & 1.00000 & 1.00000 & 1.00000 & 0.95135 & 0.98714 & 1.00000 & 0.72772 & 0.65642 \\
\hline 2 & 1.00000 & 1.00000 & 1.00000 & 1.00000 & 1.00000 & 1.00000 & 1.00000 & 1.00000 & 1.00000 & 1.00000 \\
\hline 3 & 1.00000 & 1.00000 & 1.00000 & 0.94325 & 1.02843 & 0.91009 & 0.93158 & 0.94245 & 0.96339 & 0.58185 \\
\hline 4 & 1.00000 & 1.00000 & 1.06016 & 1.00000 & 1.09148 & 0.96461 & 0.98755 & 1.00000 & 1.02144 & 0.64887 \\
\hline 5 & 1.00000 & 1.00000 & 0.97235 & 0.91618 & 1.00000 & 0.87509 & 0.87458 & 0.91656 & 0.93611 & 0.57705 \\
\hline 6 & 1.05114 & 1.00000 & 1.09879 & 1.03668 & 1.14274 & 1.00000 & 1.00000 & 1.00000 & 1.05882 & 0.69034 \\
\hline 7 & 1.01303 & 1.00000 & 1.07344 & 1.01261 & 1.14341 & 1.00000 & 1.00000 & 1.00000 & 1.03429 & 0.65980 \\
\hline 8 & 1.00000 & 1.00000 & 1.06107 & 1.00000 & 1.09104 & 1.00000 & 1.00000 & 1.00000 & 1.02149 & 0.64851 \\
\hline 9 & 0.46505 & 1.00000 & 1.03800 & 0.97901 & 1.06825 & 0.94444 & 0.96685 & 0.97896 & 1.00000 & 0.63036 \\
\hline 10 & 1.52342 & 1.00000 & 1.71865 & 1.54115 & 1.73294 & 1.44857 & 1.51560 & 1.54200 & 1.58639 & 1.00000 \\
\hline
\end{tabular}

Table 6. Cross Efficiency Matrix

\begin{tabular}{|c|c|c|c|c|c|c|c|c|c|c|}
\hline \multirow{2}{z}{} & 1 & 2 & 3 & 4 & 5 & 6 & 7 & 8 & 9 & 10 \\
\hline 1 & 0.80480 & 0.96559 & 0.74724 & 0.77768 & 0.73336 & 0.80213 & 0.78421 & 0.77752 & 0.76651 & 0.96564 \\
\hline 2 & 0.78150 & 1.00000 & 0.75145 & 0.78205 & 0.73748 & 0.80664 & 0.78862 & 0.78189 & 0.77082 & 0.97107 \\
\hline 3 & 0.80923 & 1.00000 & 0.77384 & 0.80979 & 0.76364 & 0.83525 & 0.81659 & 0.80962 & 0.79816 & 1.00000 \\
\hline 4 & 0.77714 & 0.96560 & 0.74725 & 0.80536 & 0.73337 & 0.80214 & 0.78422 & 0.77753 & 0.76652 & 0.96565 \\
\hline 5 & 0.82392 & 1.02378 & 0.79222 & 0.82449 & 0.75946 & 0.85041 & 0.83141 & 0.82432 & 0.81265 & 1.00000 \\
\hline 6 & 0.81600 & 1.00000 & 0.78461 & 0.81657 & 0.77003 & 0.83068 & 0.82342 & 0.81640 & 0.80484 & 1.00000 \\
\hline 7 & 0.83498 & 1.00000 & 0.80284 & 0.83555 & 0.78793 & 0.86182 & 0.81212 & 0.83537 & 0.82354 & 1.00000 \\
\hline 8 & 0.77714 & 0.96560 & 0.74725 & 0.77769 & 0.73337 & 0.80214 & 0.78422 & 0.80519 & 0.76652 & 0.96565 \\
\hline 9 & 0.78851 & 0.97974 & 0.75818 & 0.78906 & 0.74409 & 0.81387 & 0.79569 & 0.78890 & 0.79379 & 0.97977 \\
\hline 10 & 0.78263 & 0.97244 & 0.75254 & 0.78319 & 0.73855 & 0.80781 & 0.78976 & 0.78303 & 0.77194 & 1.00000 \\
\hline
\end{tabular}

\subsection{Ranking for Operator Allocation Alternatives}

Finally the results of AHP/DEA and DEA Cross Efficiency model and the ranking of all alternatives are obtained. Table 7 shows the ranking for operator allocation alternatives. As can be seen from Table 7, the best operator allocation alternative based on AHP/DEA is Alternative 10 and based on DEA Cross Efficiency is Alternative 2. For AHP/DEA model, it is best to allocate two operators for each operation with one assembly line. Meanwhile, the best allocation is two operators for each operation with two assembly lines when using the DEA Cross Efficiency model. The question arises now is that which model will be chosen? When we look closely at the total number of operators, we can see that the alternative given by the AHP/DEA model is more practical since it has fewer number of operators and only use one assembly line. This subsequently will reduce the cost involved.

Table 7. The result of AHP/DEA and DEA Cross Efficiency

\begin{tabular}{|c|c|c|c|c|}
\hline $\begin{array}{c}\text { Alternative, } \\
\text { DMU }_{0}\end{array}$ & $\begin{array}{c}\text { AHP/DEA } \\
\text { (Eigen vector) }\end{array}$ & Rank & $\begin{array}{c}\text { DEA } \\
\text { Cross } \\
\text { (Efficiency } \\
\text { Average of } \\
\text { all } E_{p t} \text { ) }\end{array}$ & Rank \\
\hline 1 & 0.09242 & 7 & 0.79958 & 7 \\
\hline 2 & 0.10050 & 2 & 0.98728 & 1 \\
\hline 3 & 0.09185 & 8 & 0.76574 & 9 \\
\hline 4 & 0.09664 & 6 & 0.80014 & 5 \\
\hline 5 & 0.08961 & 10 & 0.75013 & 10 \\
\hline 6 & 0.09973 & 3 & 0.82129 & 3 \\
\hline 7 & 0.09823 & 4 & 0.80103 & 4 \\
\hline 8 & 0.09712 & 5 & 0.79998 & 6 \\
\hline 9 & 0.08964 & 9 & 0.78753 & 8 \\
\hline 10 & 0.14426 & 1 & 0.98478 & 2 \\
\hline
\end{tabular}




\section{Conclusion}

Using DEA model we can identify which alternative is efficient or inefficient. We can rank the DMUs based on the largest number of efficient DMU become a reference set of inefficient DMUs. But if the efficient DMUs have the same number of reference set, AHP/DEA or DEA Cross Efficiency can be used to rank DMUs. Using AHP/DEA and DEA Cross Efficiency we can rank the alternative and can suggest to the management of the company the best operator allocation alternative. For future improvement of this research and to get more information in determining the best operator allocation, different approach can be applied and other operational constraints will be included.

\section{References}

Azadeh, A., Anvari, M., Ziaei, B., \& Sadeghi, K. (2010). An integrated fuzzy DEA-fuzzy C-means simulation for optimization of operator allocation in cellular manufacturing systems. The International Journal of Advanced Manufacturing Technology, 46, 361-375.

Azadeh, A., Kor, H., \& Hatefi, S.-M. (2011a). A hybrid genetic algorithm-TOPSIS-computer simulation approach for optimum operator assignment in cellular manufacturing systems. Journal of the Chinese Institute of Engineers, 34(1), 57-74.

Azadeh, A., \& Nazari-Shirkouhi, S. (2011b). A unique fuzzy multi-criteria decision making: computer simulation approach for productive operators' assignment in cellular manufacturing systems with uncertainty and vagueness. Journal Advanced Manufacturing Technology, 56, 329-343.

Charnes, A., Cooper, W. W., \& Rhodes, E. (1978). Measuring the efficiency of decision making units. European Journal of Operational Research, 2(6), 429-444.

Doyle, J., \& Green, R. (1994). Efficiency and cross-efficiency in DEA: Derivations, meanings and uses. The Journal of Operational research Society 45(5), 567-578.

Ertay, T., \& Ruan, D. (2005). Data envelopment analysis based decision model for optimal operator allocation in CMS. European Journal of Operational Research, 164(3), 800-810.

Krishnan, K. K., Mirzaei, S., \& Pachaimuthu, S. M. S. (2012). Risk based worker allocation. Journal of Supply Chain and Operations Management, 10(2), 139-162.

Majozi, T., \& Zhu, X. X. (2005). A combined fuzzy set theory and MILP approach in integration of planning and scheduling of batch plants-Personnel evaluation and allocation. Computers \& Chemical Engineering, 29(9), 2029-2047.

Saaty, T. L. (1980). The Analytic Hierarchy Process, Mc Graw-Hill, New York.

Sinuany-Stern, Z., Mehrez, A., \& Hadad., Y. (2000). An AHP/DEA Methodology for Ranking Decision Making Units. International Transactions in Operational Research, 7, 109-124.

Yang, T., Chen, M.-C., \& Hung, C.-C. (2007). Multiple attribute decision-making methods for the dynamic operator allocation problem. Mathematics and Computers in Simulation, 73(5), 285-299.

Zohrehbandian, M., Abbasian-Naghneh, S., Fardi, M., \& Moradi, E. (2011). A New Approach for Optimal Operator Allocation in Cellular Manufacturing Systems. Australian Journal of Basic and Applied Sciences, 5(12), 2709-2715. 
R. Mat Rani, W. Rosmanira Ismail/ Operator allocation selection in labor-intensive 